\title{
Non-in situ heart-lung transplantation: doing less may prove to be worth it
}

\author{
Jason O. A. Thomas, Pedro Catarino \\ Department of Cardiac Surgery, Smidt Heart Institute, Cedars-Sinai Medical Center, Los Angeles, CA, USA \\ Correspondence to: Pedro Catarino, MD, FRCS. Department of Cardiac Surgery, Smidt Heart Institute, Cedars-Sinai Medical Center, Los Angeles, \\ CA, USA. Email: Pedro.catarino@cshs.org. \\ Comment on: Xu X, Shi J, Peng G, et al. Non-In Situ Technique of Heart-Lung Transplantation: Case Series and Technique Description. Ann Thorac \\ Surg 2021;112:661-4.
}

Submitted Sep 11, 2021. Accepted for publication Sep 28, 2021.

doi: 10.21037/jtd-21-1490

View this article at: https://dx.doi.org/10.21037/jtd-21-1490

Many a cardiac surgeon would revel at reporting that their patient, "underwent a heart-lung transplant with an uncomplicated operative and post-operative course." However, these praises typically do not follow such large and increasingly rare operations [less than 60 adult procedures are recorded by the ISHLT Registry each year (1)]. The implantation is rather graceful, requiring less anastomoses in comparison to an orthotopic heart transplant. The explantation, on the other hand, leans more difficult in the appropriate population. Nevertheless, heartlung transplantation (HLTx) remains the best and often the only treatment for patients with concomitant end-stage heart and lung disease. The technique, first performed in 1981, largely has been devoid of widespread modification despite using maneuvers that, even with appropriate caution, increase the frequency of several intraoperative complications (2-4). Namely, uncontrollable mediastinal bleeding and phrenic nerve injuries pose significant challenges inherent to the procedure that ultimately translate to increased morbidity and mortality. Despite a handful of operative modifications that seek to curtail these concerns being reported in the literature, a market for innovation still exists. $\mathrm{Xu}$ and colleagues offer an approach to addressing this in their study, suggesting that doing less is ultimately beneficial (5).

In the article titled "Non-In Situ Technique of HeartLung Transplantation: Case Series and Techniques", Xu and colleagues describe their series comparing the outcomes of traditional HLTx technique to their non-in situ modification (5). In this single center retrospective series,
15 patients without prior heart surgery between September 2015 and September 2020 underwent a HLTx. The first 12 patients received the traditional operation and served as the controls, while the chronologically latter three received the new approach. The study showed that non-in situ HLTx allowed for decreased total operative and donor ischemic times, less intraoperative bleeding and transfusions, as well as reduced ICU and hospital stays when compared to traditional HLTx. Of note, one non-in situ HLTx patient passed on day 7 suggested secondary to complications form complex management of a concomitant kidney transplant.

A comment must be made on the difficulty of generalizing a series involving three patients, without the possibility of any matching, on outcomes, two of which were not attainable in at least one patient. Similarly, assessing the influence of improved technical and managerial expertise from having treated more HLTx patients prior to offering and performing the new approach, proves another limitation.

Papers that offer novel approaches are subject to the criticism of performing operations on patients without the proper indications. The indications for HLTx have become more stringent over recent years now mainly including congenital heart disease with Eisenmenger syndrome (ES), and idiopathic pulmonary arterial hypertension (IPAH) and cystic fibrotics with significant right ventricular or left ventricular impairment (6). Reassuringly, the three nonin situ HLTx patients were appropriately selected: patient 1 with an atrial septal defect and ES [although more recent data may suggest otherwise (7)], patient 2 with $\mathrm{PAH}$ and heart failure from significant multivalvular disease, and 
patient 3 with patent ductus arteriosus, ES, valvular disease and infective endocarditis. This adds much support to $\mathrm{Xu}$ and colleagues' reported results. Although none of the cases were in patients with previous cardiac surgery, the technique may actually benefit the "redo" situation the most.

What distinguishes non-in situ HLTx from the traditional technique described by Jamieson and colleagues (2)? Well, the new technique most differs from the original in two immediately apparent ways. Firstly, it avoids dissecting the collateral rich posterior aortopulmonary-left atrial region and the highly vascular peri-carinal region, seen in these patients, from the posterior mediastinum. This circumvents issues with the tedious fight for hemostasis by leaving remnants of the left atrium, pulmonary artery, and carina in the recipient. This also reduces risk of injury to the seldom visualized vagus nerve running posterior to the main bronchi, protection of which largely relies on blunt dissection. Secondly, it avoids creating phrenic nerve pericardial pedicles under which the lungs of the heartlung block are passed, now placing the heart-lung block entirely anterior to the phrenic nerves. This reduces the extent of phrenic nerve dissection and manipulation, in turn preventing unnecessary injury.

The novelty of this technique is not immediately evident. Similar technical approaches have previously been reported in isolation. In response to the need for hemostasis, as highlighted in this study, Losman described then emerging techniques whereby the left atrial back wall was left in situ and the technique used by Cabrol and colleagues whereby the pulmonary artery bifurcation and carinal back wall were left in place (8). Likewise, Icenogle and Copeland described placement of the heart-lung block anterior to the phrenic nerves, although not to portend nerve injury, but as a method to easily improve posterior mediastinal exposure and address bleeding following implant, without any adverse sequalae from this technique (9). Even then, we have come a long way in use of hemostatic technology and approaches to dealing with bleeding when they arise, although any avoidance of such issues is always welcomed (10-12).

The novelty then of non-in situ HLTx lies more in the combination of the two approaches and in leaving the intact carinal element: the stapled bronchi with a sterilized and oversewn distal tracheal segment. As with any new technique, much scrutiny should be given to the added benefits and drawbacks as compared to the traditional approaches. Questions about the perioperative-, short-, and longer-term risks of the carinal remnant were not explicitly addressed within the study. However, the 1- and 6-month follow-up CT imaging showed promising reduction in size of the remnant without apparent signs suggestive of a collection, brewing infection, or necrotic mass. Cardiac herniation through the left phrenic pedicle posed a not uncommon issue in the traditional technique, a concern for reduction of systemic venous return. Will the lack of membrane between the heart and lungs increase the frequency of this? Icenogle and Copeland described a similar tendency in their anterior heart-lung block placement, for the heart to fall into the left chest unless supported, which suggests that non-in situ HLTx may be subject to similar hindrances, although not directly discussed here (9). Of note, positioning of the heart was maintained once lungs were ventilated.

As surgeons, the need to continually improve upon surgical technique for better outcomes is always present. $\mathrm{Xu}$ and colleagues offer a new approach to HLTx to address issues that remain troublesome for many transplant cardiac surgeons. The technique demands less doing from the surgeon and suggests better outcomes may result. Questions remain about the long-term impacts of the approach, although these initial promising results offer some assurance for better days for both patients and surgeons. Ultimately, additional data are required before any new technique achieves widespread acceptance.

\section{Acknowledgments}

Funding: None.

\section{Footnote}

Provenance and Peer Review: This article was commissioned by the editorial office, Fournal of Thoracic Disease. The article did not undergo external peer review.

Conflicts of Interest: Both authors have completed the ICMJE uniform disclosure form (available at https://dx.doi. org/10.21037/jtd-21-1490). The authors have no conflicts of interest to declare.

Ethical Statement: The authors are accountable for all aspects of the work in ensuring that questions related to the accuracy or integrity of any part of the work are appropriately investigated and resolved.

Open Access Statement: This is an Open Access article distributed in accordance with the Creative Commons 
Attribution-NonCommercial-NoDerivs 4.0 International License (CC BY-NC-ND 4.0), which permits the noncommercial replication and distribution of the article with the strict proviso that no changes or edits are made and the original work is properly cited (including links to both the formal publication through the relevant DOI and the license). See: https://creativecommons.org/licenses/by-nc-nd/4.0/.

\section{References}

1. Chambers DC, Cherikh WS, Goldfarb SB, et al. The International Thoracic Organ Transplant Registry of the International Society for Heart and Lung Transplantation: Thirty-fifth adult lung and heart-lung transplant report-2018; Focus theme: Multiorgan Transplantation. J Heart Lung Transplant 2018;37:1169-83.

2. Jamieson SW, Stinson EB, Oyer PE, et al. Operative technique for heart-lung transplantation. J Thorac Cardiovasc Surg 1984;87:930-5.

3. Pigula FA, Gandhi SK, Ristich J, et al. Cardiopulmonary transplantation for congenital heart disease in the adult. J Heart Lung Transplant 2001;20:297-303.

4. Ferdinande P, Bruyninckx F, Van Raemdonck D, et al. Phrenic nerve dysfunction after heart-lung and lung transplantation. J Heart Lung Transplant 2004;23:105-9.

5. Xu X, Shi J, Peng G, et al. Non-In Situ Technique of

Cite this article as: Thomas JOA, Catarino P. Non-in situ heart-lung transplantation: doing less may prove to be worth it. J Thorac Dis 2021;13(10):5579-5581. doi: 10.21037/jtd-211490
Heart-Lung Transplantation: Case Series and Technique Description. Ann Thorac Surg 2021;112:661-4.

6. Weill D, Benden C, Corris PA, et al. A consensus document for the selection of lung transplant candidates: 2014--an update from the Pulmonary Transplantation Council of the International Society for Heart and Lung Transplantation. J Heart Lung Transplant 2015;34:1-15.

7. Sertic F, Han J, Diagne D, et al. Not All Septal Defects Are Equal: Outcomes of Bilateral Lung Transplant With Cardiac Defect Repair vs Combined Heart-Lung Transplant in Patients With Eisenmenger Syndrome in the United States. Chest 2020;158:2097-106.

8. Losman JG. Heart-lung transplantation. J Thorac Cardiovasc Surg 1985;89:807-9.

9. Icenogle TB, Copeland JG. A technique to simplify and improve exposure in heart-lung transplantation. J Thorac Cardiovasc Surg 1995;110:1590-3.

10. Vouhé PR, Dartevelle PG. Heart-lung transplantation. Technical modifications that may improve the early outcome. J Thorac Cardiovasc Surg 1989;97:906-10.

11. Novick RJ, Menkis AH, McKenzie FN, et al. Reduction in bleeding after heart-lung transplantation. The importance of posterior mediastinal hemostasis. Chest 1990;98:1383-7.

12. Roselli EE, Smedira NG. Surgical advances in heart and lung transplantation. Anesthesiol Clin North Am 2004;22:789-807. 